\title{
Uprooted: A conversation with Artist Yang Yi ${ }^{1}$
}

\author{
YANG Jingi
}

\begin{abstract}
Chinese photo artist Yang Yi was born in a small town by the Yangtze River. His Uprooted series made in 2007 foreshadowed the inundation of his hometown due to the construction of Three Gorges Project and the loss and preservation of memories. For Yang Yi, the Three Gorges Project not only inundated the physical space, but affected all of life and di srupted a l ong hi st ory and tradi ti on of hi s honet own Yang Yi has participated in many solo and group exhibitions in China and abroad. In 2010, he was selected to be one of that year's PDN $30 \mathrm{New}$ and Emerging Photographers to Watch.
\end{abstract}

Yang Jing: Your photo series Uprooted was reported by many online and newspaper media. In 2010, you were selected to be one of that year's PDN 30 New and Emerging Photographers to Watch. Can you say something about the conception and production of this series?

Yang Yi: Uprooted was about my hometown Kaixian. My deep affection for my hometown was the primary motive to make this work. After graduating from university, I worked more than 10 years in advertising. I was always fond of photography. In 2005, I got to know that the demolition in Kaixian had begun, but I had no idea when the old town was to be inundated. I planned to record those that were to disappear forever. I had a deep feeling to the Three Gorges. I was born and brought up in Kaixian and I studied in Wuhan for my university education. Every time I took a steamship along the Yangtze River, I needed to pass by the Three Gorges. I was so familiar with those places, such as Yuyang, Fengjie and Zigui. In 2005 I started shooting and I went several times to my hometown and had a complete journey along the Three Gorges. I had little knowledge about photography then. After taking a lot of black and white photos, I even didn't know how to develop the films and I had to ask help from my friends.

At that time, I was quite hesitant. After working so many years as an AD designer, I felt tired of my job and I was planning to become a freelance photographer. In 2006, I went to study photography at CAFA. Yao Lu was my teacher. I studied very hard, either working in the dark room, or discussing photography with my teachers and classmates, or looking at different exhibitions. For my graduation work practice, I had a plan to shoot my hometown. However, I was not satisfied with the photographs that I took in 2005. Although some photos were good in composition and the use of light, I

\footnotetext{
${ }^{1}$ Yang Jing is an art researcher from China. She is currently undertaking a post-doctoral research at Department of Music, Art and Culture Studies of University of Jyväskylä, focusing on ecological awareness in Chinese contemporary art.
} 
realized that documentary photos were not what I wanted. My initial idea was to record the shoot the Three Gorges and leave the record of it to my friends and future kids, but after one year studying at CAFA I had a deeper understanding of photography and I thought that my idea was rather superficial. I decided to reshoot the Three Gorges, but in another way. So, later, I made this series to express my feeling for the impending submergence of my hometown.

Yang Jing: When did you start and complete this series?

Yang Yi: From 2007 to 2008. Strictly speaking, the preparatory work in 2005 should be included. The shooting started in June 2007 and was completed by the end of 2008. It took about one and a half years. Most artists who took the Three Gorges as their subject chose the documentary approaches to record the people and scenes. I was the first one to make use of a surrealist expression. This project is not only about the Three Gorges; in China today, everybody might have the experience of demolition and relocation, for instance, with your school or your home being demolished. This is a common memory, so it found echoes in people's hearts.

Yang Jing: How many works does the series Uprooted include?

Yang Yi: 24. Not so many. Because I felt I had expressed enough of what I wanted to say through these photos, so there was no sense in making more.

Yang Jing: How about the exhibitions of this series?

Yang Yi: This series was widely exhibited, both at home and abroad. For instance, in 2009, this series was exhibited at Multi-Dimensional View: Chengdu Contemporary Photo Exhibition. In 2012, this series was exhibited at Rising Dragon: Contemporary Chinese Photography at Katonah Museum of Art, New York. And it has been exhibited at the Chinese Contemporary Art Exhibition at Museum Jan van der Togt in Amsterdam. I also had solo exhibitions at the Paris-Beijing Photo Gallery in Beijing, the M17 Gallery in Shanghai, the DIX9 Gallery in Paris, and Galerie Richard in New York, among others.

Yang Jing: I first noticed this series in 2009. The dreamlike photos in which people wearing snorkel masks look as if they are living underwater are very impressive though oppressive. How did you get the idea to shoot them underwater?

Yang Yi: It was from my dream. It was such a pity that such a lovely town was to be submerged. I was in Beijing at that time, and one night I had a dream in which a lot of people, some I knew and some I didn't know, with furniture, clothes, and other items were inundated and suspended in water. This is the so called phenomenon that "What you think about in the day, you will dream of at night". I suddenly woke up and immediately wrote down the scenes that had appeared in my dream and made some 
sketches. I guess that dream was a subconscious sign of my accumulated anxieties about my hometown and memory and I must express my anxieties through art. I always had an interest in dream in works of art. For example, my favorite film artist Tarkovsky's works are often dreamlike. The people wearing masks stayed underwater, where the abandoned empty town was the place where they once lived. They played Mahjong, had their hair cut and chatted in such familiar scenes, keeping their former life going on. My teacher was pleased with my idea. Sometimes I think if I had gone there a year earlier and the demolition hadn't yet started and I couldn't have shot what I wanted; if I had gone there one year later, the whole town would have disappeared. It seems that everything was decided so that I did this at a right moment. When I went to shoot, the demolition had already started. I saw all kinds of shocking slogans such as "Fight for one hundred days, demolish half the old town!" The half torn down old town was reduced to a huge amount of debris, and it was filled with an atmosphere of decay and death. I pressed the shutter again and again and I wanted to escape as soon as possible. In 2009, as the last inundated county in the reservoir area, the old town of Kaixian with its 1800 years of history was submerged under water.

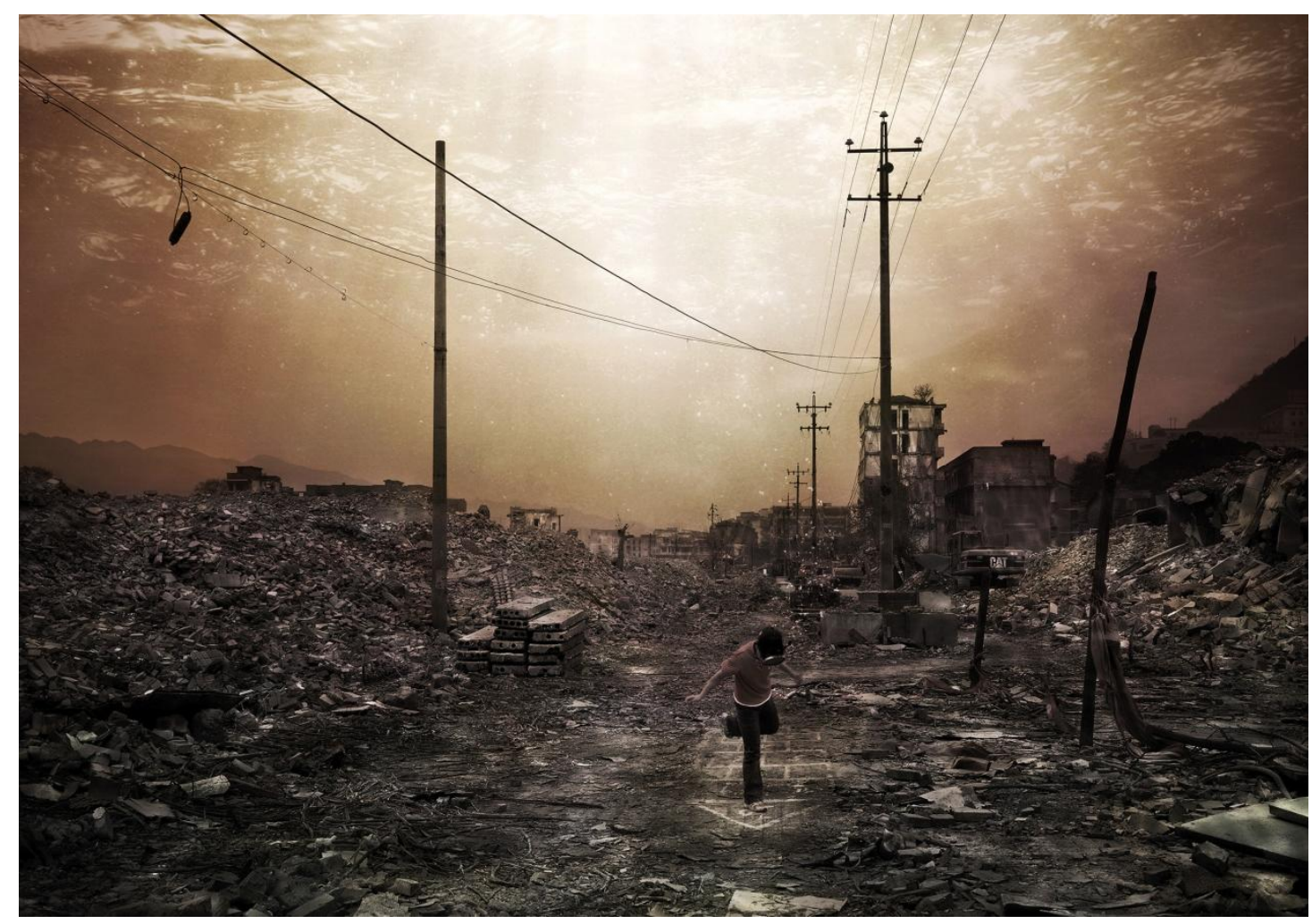

Uprooted \#6, Old City: New Street Corner, 2008, courtesy of the artist.

Yang Jing: The series Uprooted really reminds us of a dream. Ghost like people are wandering in such a spacious underwater world and the tone is gloomy and grave. How did you make such surrealistic pictures technically?

Yang $\mathrm{Yi}$ : It was not too difficult. The only challenge was the requirement for cooperation from the people who were being photographed. This took place in 
summer, so it was uncomfortable to wear the mask, and many people didn't want be photographed. I explained my idea to them, my fellow villagers. When they understood what I wanted to do, they were very cooperative. I couldn't actually create an underwater scene, and if I had tried the subjects would not be visible. I couldn't recreate the reality, but I needed to make it look like a real underwater scene. Many details were taken into consideration. The human figures and town scenes were all shot on site. Then, I prepared a huge glass water tank so that I could shoot the waves, bubbles and the bended light rays into the water. Then, I dealt with these in Photoshop. I combined the local shooting and the water bubbles and the refracted light rays. It was not technically difficult to realize my idea.

Yang Jing: Are these photos on the wall your recent work?

Yang Yi: This series is titled Still Life. In front of such a white background I shot different daily life items, such as a candle, a knife, a capsule, a flashlight etc. In this calm scene I seek to express the conflict and contradiction in an indirect way. For example, in this photo, the flame of the candle was replaced by the bleeding blade. Such a surrealist visual expression carries metaphorical meaning.

Yang Jing: A lot of photographers and video artists concentrate on the social issues, including ecological and environmental problems. Your work relates to the Three Gorges. Can you explain your own understanding of the ecological and environmental crisis?

Yang Yi: First, an artist should be sensitive. Art presents an outlet for the concern and anxiety about reality. Living in contemporary China, I must express my concern and anxiety. People are more aware of the environmental issues, because the degradation and destruction of the environment is becoming a bigger threat to people. In our lives, we see more and more people, even young people, suffering cancers due to environmental pollution. Another point is that there is a loss of spiritual land so that we have no place to install and save our feelings. The Three Gorges Project has caused severe environmental destruction. When I was working on the Uprooted series, I read a book written by Huang Wanli who was a famous hydraulic scientist. As an intellectual, all his life he was against the construction of the dam. What has happened so far has proved his predictions and worries. Another, the consequent large scale relocation and migration caused huge social problems. The inundated land was $632 \mathrm{~km}^{2}$ and affected 20 towns, counties and cities. Several times I went abroad for exhibitions, I exchanged my idea with the audiences and they were surprised by that it could be possible to so easily demolish such a large place. But this is common in China. So, people not only lose their physical hometown, but also their spiritual home. That is a painful memory. The case of Kaixian is called in-situ reconstruction, which means that the town at an altitude of below 175 meters was inundated, and a new town was rebuilt at the higher elevations. The new town is much bigger than the old one. But nowadays, when I go back home, I feel the new town has 
nothing to do with me, because the places I remember have all memories are gone. As I wrote in an essay, "36 years ago, I was born there. When I wake up from a long sleep, everything is under water..." And the new town is noisy, filled with vulgar buildings. People who live there now are mentally impetuous. Many people have nothing to do but eat, drink and play Mahjong every day.

Mr. Gu Zheng once summarized the meanings of this series. He wrote in one article that the Three Gorges Project not only inundated the physical space, but also affected all of life and the long history and traditions of the place. A life is bound to a specific space; but when the space is uprooted, the memory disperses. He thinks there are three levels of information in this title. The first is "submerge", the second is "sink" or "disappearance" and the third is "confiscation", the confiscation of our hometown. But what the power of the state confiscated from us was not only our property, but also our emotions and memories. I think that was good analysis. This project is an environmental and social disaster. The translation of "Uprooted" is perfect, as it means not only physically destroying the environment, but also uprooting the memory.

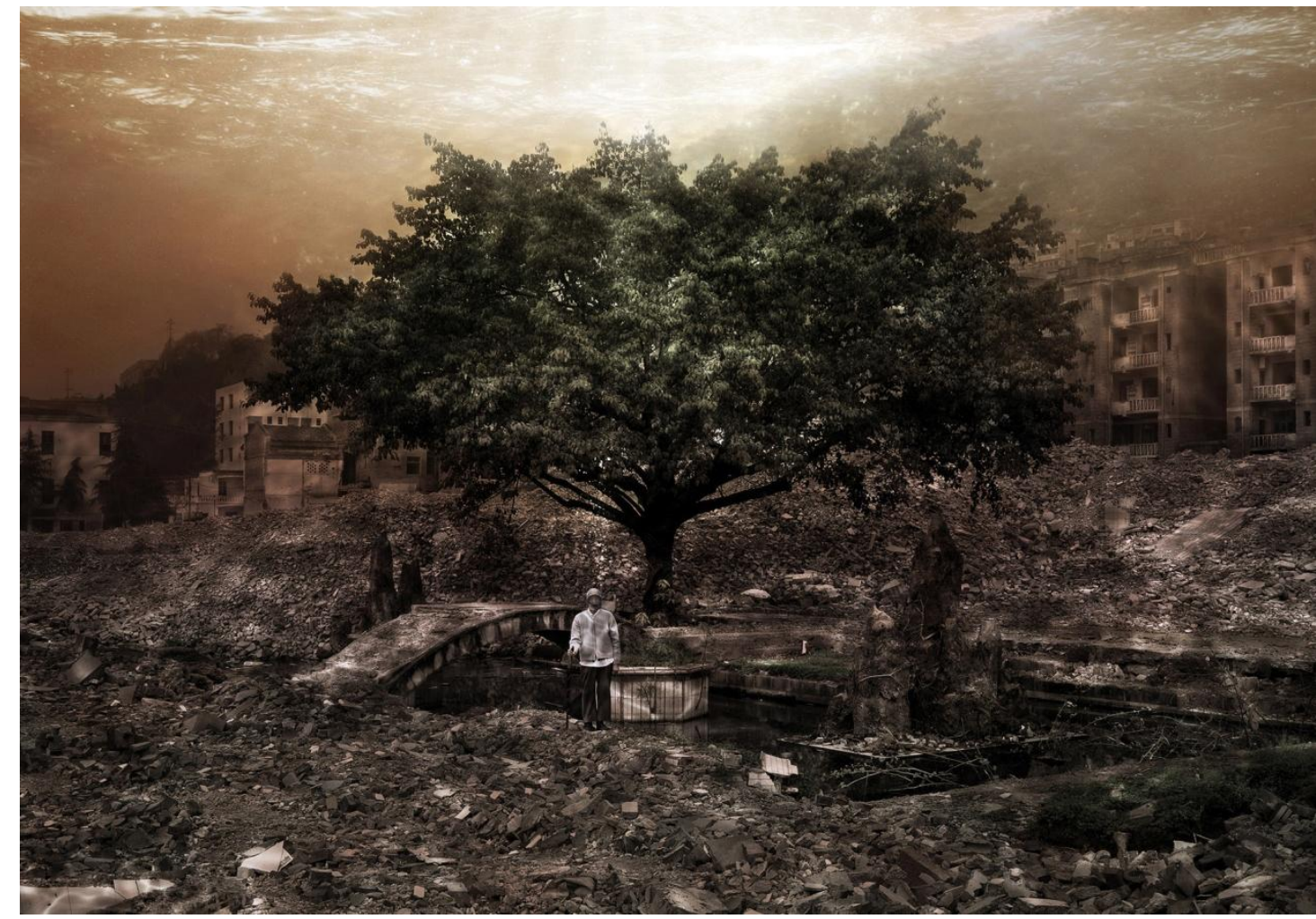

Uprooted \#18, Old City: Guest House at Communal Government, 2008, courtesy of the artist.

Yang Jing: How did you continue your awareness of ecological and environmental issues after the Uprooted series?

Yang Yi: My later work still relates to the Three Gorges. Uprooted was only about my hometown Kaixian. The second series, but not yet uncompleted, was about the whole 
Three Gorges region. It is about the historical legendary people of many spaces in this region, such as the poet Li Bai and Baidi town, Qu Yuan and Zigui town, and General Bai Manzi and Yunyang town. In addition, Uprooted shot underwater, but the second series is about the landscapes above water. I have made a couple of works. But I'm not so satisfied with the effect, so I haven't published them. These years, I have been making installations, paintings and small animations too.

Yang Jing: The construction of the Three Gorges Dam is completed. This project highlighted the conflict between humans and nature in a broad meaning, in this case specifically the conflict between the local people's living environment and the construction of a mega-scaled hydraulic project under the name of modernization. This relates to the conflict between development and preservation. How do you see the role of artists in these conflicts?

Yang Yi: Contemporary art emerged in China in accordance with the economic development of the 1990s. It naturally has a close relationship with ecological and environmental issues. Some art works don't express this, of course. Living in such an environment full of problems, we can never neglect or ignore the reality. I believe that contemporary art must engage in the social reality. If an artist's work isn't involved with these issues, it's not contemporary art, even though it's still art. I'm not so sure if my idea is correct. Personally, I think that good art works should be critical, some more directly, some more implied.

Actually, many ecological and environmental problems, such as food security, traffic jams, smog and water pollution, are all political if we look deeply. Living in such a society, an artist has the right, as well as the responsibility, to express his concern about social issues. I don't think an artist should just focus on making visually pleasing art pieces. We should express our social concern, instead of glamorizing the situation. Of course, an artist must choose an artful way to engage in the social issues, he should be metaphorical and skillful, with his own unique language.

Yang Jing: Exactly. Nobody can really avoid ecological and environmental problems. Do you think there is conflict for an artist between conveying his environmental concerns and making aesthetic work?

Yang Yi: Aesthetic work can express environmental concerns. For example, I rather appreciate the British artist Andy Goldsworthy's land art works. He used to use leaves, twigs, ice and all kinds of natural materials to make art. His work is visually pleasing, but at the same time it contains deep environmental concerns, though his method is not directly critical. So, there are different ways for artists to express their environmental awareness. Another, British photographer Nadav Kander influenced a lot of Chinese photographers. He photographed the Yangtze River from the river estuary up to its headstream. His Yangtze, the Long River series includes a lot of construction sites and debris, but the images are poetic, and the tone is very nice. His 
works cause a heart-breaking feeling: how can the human beings destroy such beautiful places?

Yang Jing: Which artists, of course not necessarily in photography, have had a big influence upon you?

Yang Yi: At the beginning, the Magnum photographers had a relatively big influence on me. For example, I rather like the works of Josef Koudelka. The German photographer August Sander's work inspired me as well. I love free and emotional art. My favorite artists are the Mexican female artist Frida Kahlo and American graffitist Jean-Michel Basquiat. Among film artists, Andrei Tarkovsky had a deep influence on me. I also enjoyed watching the movies made by the Serbian filmmaker Emir Kusturica. I also like Jia zhangke's early works, but I think his later works are just so so. Among Chinese contemporary artists, I like Shang Yang's work most. His hometown was Kaixian. I think his work is not only skillful, but also reached a high level spiritually. The conscientiousness and calmness in his work reminded me of those ancient masters. His paintings express scholarly thinking about human destiny with a continuous focus on environmental issues. As an artist born in the 1940s, he extricated himself from the influence of the Soviet style a long time ago. He has been always going forward; his exploration of image style, material and texture is never ending.

Yang Jing: Actually, since I started this research project, I have noticed that there are a much more significant number of photographers and video artists than I at first thought.

Yang Yi: In Chinese contemporary art circles, photography and video are still more or less neglected. A lot of artists think that photography is only for collecting material for their creation and it is very simple in this digital era. There are many influential photographers and video artists in Chengdu, but most people value only easel painting. As we have said, art has something to do with social concerns. Photography and video, because of the timely and on-the-spot report, together with the close connection to mass media, are more related to the expression of social issues. Another point is that social acceptance is also related to the expression of social concern. For example, installation and performance are very common in contemporary art for expressing social concerns. But in China performance and installation are somehow restrained and also a lot of people don't understand installation and performance art. Therefore, their social impact is limited.

Yang Jing: Chinese contemporary artists paid a lot of attention to the issue of demolition and relocation. Your work, in essence, is also about demolition and relocation. There is even a term, demolition aesthetics, for describing these works. What do you think of the interest of Chinese artists in demolition and relocation? 
Yang Jing: This is the first time I have heard the term "demolition aesthetics". I have some reservations about this view and I have no comment on it. In reality, demolition and relocation are the most popular topics in newspapers, on TV and on the internet now. Without the fast development of real estate, there would be no large-scale demolition. So, demolition and relocation speak of the speeded development of the past three decades. I think it's natural that it has become the subject for many artists. I know that the work of many artists, such as Yao Lu and Wang Jinsong's, is concerned with demolition. Each artist has his own perspective and language. The demolition and relocation of the Three Gorges Dam, as Gu Zheng mentioned, is the expression and practice of the power of the state, which changed the local ecology and environment as well as people's spiritual and mental situation.

Behind the demolition and relocation is the problem of over exploitation. We don't say that economic development was wrong. However, lacking of the rule of law, China lost the balance between development and preservation. For example, the policy of "Whether a white cat or a black cat, it is a good cat that catches mice" caused the mushrooming of many rural and small town industries. Caring only short-term profits, the rural and small town enterprises caused huge ecological and environmental disasters in China. Furthermore, the trust between people has been destroyed, and money fetishism has become the one and only concern. This huge destruction of nature and the environment started from the 1990s. So, the expression of demolition and relocation became the focus of many Chinese artists, which was different from the focus of Western ecological artists.

\footnotetext{
i This interview with Yang Yi was conducted on 15 April, 2016. The interview was originally in Chinese and translated into English by the author. The Chinese transcript was reviewed and approved by artist Yang Yi and kept in the possession of the author.
} 